\title{
Continuing, Withdrawing, and Withholding Medical Treatment at the End of Life and Associated Characteristics: a Mortality Follow-back Study
}

\author{
Yolanda W. H. Penders, $P h D^{7}$, Matthias Bopp, PhD, $\mathrm{MPH}^{7}$, Ueli Zellweger, $M \mathrm{MC}^{7}$, and \\ Georg Bosshard, MD² for the Swiss Medical End-of-Life Decisions Study Group
}

'Epidemiology, Biostatistics and Prevention Institute, University of Zurich, Zurich, Switzerland; ${ }^{2}$ Clinic for Geriatric Medicine, Zurich University Hospital, and Center on Aging and Mobility, University of Zurich and City Hospital Waid, Zurich, Switzerland.

BACKGROUND: Studies on forgoing treatment often ignore treatments that are continued until death.

OBJECTIVE: To investigate how often specific treatments are withdrawn or withheld before death and to describe the associated patient, physician, and care characteristics.

DESIGN: National mortality follow-back study in Switzerland in 2013/2014 using a standardized survey to collect information on the patient's end of life and demographics on the physician.

PARTICIPANTS: A random sample of adults who died non-suddenly without an external cause and who had met the physician completing the survey $(N=3051)$.

MAIN MEASURES: Any of nine specific treatments was continued until death, withdrawn, or withheld.

KEY RESULTS: In 2242 cases (84\%), at least one treatment was either continued until death or withheld or withdrawn. The most common treatment was artificial hydration, which was continued in $23 \%$, withdrawn in $4 \%$, and withheld in $22 \%$ of all cases. The other eight treatments were withdrawn or withheld in $70-94 \%$ of applicable cases. The impact of physician characteristics was limited, but artificial hydration, antibiotics, artificial nutrition, and ventilator therapy were more likely to be withheld at home and in nursing homes than in the hospitals.

CONCLUSIONS: Large differences exist between care settings in whether treatments are continued, withdrawn, or withheld, indicating the different availability of treatment options or different philosophies of care. While certain patient groups are more likely to have treatment withheld rather than attempted, neither patient nor physician characteristics impact the decision to continue or withdraw treatment.

KEY WORDS: palliative care; end-of-life decisions; withholding treatment; medical decision-making.

J Gen Intern Med 35(1):126-32

DOI: $10.1007 / \mathrm{s} 11606-019-05344-5$

(c) Society of General Internal Medicine 2019

Received August 24, 2018

Revised April 18, 2019

Accepted August 22, 2019

Published online October 25, 2019

\section{INTRODUCTION}

Overly aggressive treatment has been recognized as a serious impairment to quality of life in the final phase of life. Furthermore, this kind of treatment is more costly than appropriate palliative care and is viewed negatively by the patient's relatives. ${ }^{1,2}$ However, treatment such as artificial hydration and certain medications can also play an important role in maintaining an optimal quality of life until the moment of death. The time when potentially life-sustaining treatment should be dispensed with and the ethics of this decision are matters of intense debate with strong intercultural differences. ${ }^{3-5}$

The decision to forgo treatment- that is to say, to withdraw or withhold treatment before death - is often made because there is 'little chance of improvement', although specific reasons such as 'loss of dignity' are more common for certain patient groups, such as the very old and people with dementia. ${ }^{5-8}$ General population samples, i.e. those without a terminal illness, show that most people would prefer to forgo treatment in some situations. ${ }^{7}$ Previous studies using nationwide samples found that forgoing potentially life-sustaining treatment was the end-of-life decision with the greatest life-shortening impact in many countries, in up to $22 \%$ of deaths in Sweden, $23 \%$ in Denmark, and $37 \%$ in the Netherlands. ${ }^{6,9}$ In the German-speaking part of Switzerland, the decision to forgo treatment probably had the greatest life-shortening impact in $29 \%$ of deaths in 2001 , rising to $35 \%$ in $2013 .{ }^{10}$ However, all these studies prioritized medical end-of-life decisions (MELDs) according to the action that shortened life the most, which is a questionable approach, since in practice MELDs are often combined. When including cases where forgoing treatment was not the life-shortening action with the greatest impact, $70 \%$ of eligible (i.e. non-sudden, 'expected') deaths in the German-speaking part of Switzerland in 2013 were preceded by a decision to forgo treatment, although the prevalence in the French-speaking (60\%) and Italian-speaking $(57 \%)$ regions was lower. ${ }^{9,10}$

Despite interest in the topic, most clinical research investigates only those potentially life-sustaining treatments that are forgone, without taking into account how often 
treatments are continued until death. ${ }^{4,8,9,11}$ This means that the proportion of treatments such as artificial nutrition, chemotherapy, and antibiotics that are forgone or continued until death is unknown. Knowledge of such patterns will help both clinicians and patients to understand end-of-life decision-making in clinical practice and help to develop guidelines that assist their shared decision-making. Furthermore, research frequently reports on treatments forgone, without distinguishing between those that are withdrawn and those that are withheld. Many guidelines emphasize that there is no ethical difference between the two, but studies have shown that this does not correspond to the views of clinicians or the general public. ${ }^{12-14}$ In addition, the availability of treatment and support in different care settings may influence decisions to withhold (i.e. not even attempt) or to start and later withdraw a particular treatment. Grouping all these clinically different practices together may obscure important differences in the when, where, for whom, and by whom these decisions are made.

Using data from a nationwide mortality follow-back study in Switzerland, we investigated how often specific treatments were forgone among all adult deaths. We also investigated which patient and physician characteristics were associated with withdrawing or withholding the most commonly forgone treatments. Switzerland provides a good case study for investigating end-of-life decisions in a wider international context, as its statutory health insurance system combines mandatory coverage and private insurance, as found in other countries. ${ }^{15}$ Furthermore, end-of-life care in Switzerland is characterized by a strong emphasis on patient autonomy and the implementation of advance directives, which are common in other countries such as the Netherlands, Australia, and the USA. $^{16-19}$

\section{METHODS}

\section{Sample and Data Collection}

Data was collected through a nationwide mortality followback survey. The Swiss Federal Statistical Office drew a random sample of death certificates on a weekly basis between August 1, 2013, and January 31, 2014. Questionnaires were mailed to the certifying physicians. From this sample, we included data on all people who died at the age of 18 or over, when the physician who completed the questionnaire did not consider the death to have been unexpected.

\section{Survey}

A standardized survey collected information about medical end-of-life decisions regarding the patient, as well as the role (generalist vs. specialist) and duration of practice of the attending physician. Physicians indicated when they had first had contact with the patient and whether or not the patient's death was sudden and unexpected. A multiple-choice question with an open 'other' option was used to inquire about treatments that were withheld or withdrawn before death. A separate question asked whether any treatments were continued until death. We focused on nine specific treatments: artificial hydration, antibiotics, artificial nutrition, ventilator therapy, surgery, chemotherapy, blood and blood products, dialysis, and radiotherapy. Patient demographics (age, sex, and region of residence) were collected from the death certificate. The study questionnaire ${ }^{20}$ and more details are given elsewhere. ${ }^{9,10}$

\section{Analysis}

Descriptive statistics were used to yield weighted percentages with 95\% confidence intervals. Multivariable logistic regression analysis was conducted to test the association between patient, care, and physician characteristics with forgoing specific treatments. Differences in response rate were adjusted for sex, age, and region (German-speaking, French-speaking, and Italian-speaking). As previous studies have shown differences in end-of-life decision-making between the Swiss language regions, we corrected for region as well as for sociodemographic and care characteristics in our analyses. ${ }^{9,10}$ The free-text comments in the 'other' option were classified manually into existing categories wherever possible. Listwise deletion was applied to the missing values $(<1.4 \%)$.

\section{Ethics}

Consent from the patient was waived by the Zurich Cantonal Ethics Committee (KEK-StV No. 23/13).

\section{RESULTS}

\section{Description of the Study Population}

In total, 3678 deaths fulfilled the general inclusion criteria for MELDs. We excluded the deaths of those for whom no information was available on withholding, withdrawing, or continuing treatment; those with whom the physician filling in the questionnaire did not have any contact before death; and those who died from external causes (e.g. accidents). This left a final sample of 3051. The age group between 80 and 89 years was the largest (39\%; Table 1). The study population included slightly more women (54\%) than men (46\%). The most common cause of death was cancer $(30.5 \%)$, followed by cardiovascular disease (26\%) and diseases of the nervous system (19\%). Death most commonly occurred in hospitals (40\%), followed by in nursing homes $(32 \%)$, in elderly care residences $(12 \%)$, and at home (11\%). Only a small number of people died in hospices or palliative care units (5\%). Most questionnaires were completed by generalists $(67.5 \%)$ and physicians who had graduated no longer than 15 years earlier (42\%). 
Table 1 Descriptors of the Study Population: All Deaths Eligible for a Medical End-of-Life Decision with Information on Forgone or Continued Treatments $(N=3051)$

\begin{tabular}{|c|c|c|}
\hline & $n^{*}$ & $\% *$ \\
\hline \multicolumn{3}{|l|}{ Patient } \\
\hline \multicolumn{3}{|l|}{ Age } \\
\hline $18-65$ & 364 & 11.6 \\
\hline $65-79$ & 787 & 25.0 \\
\hline $80-89$ & 1167 & 38.8 \\
\hline$\geq 90$ & 733 & 24.7 \\
\hline \multicolumn{3}{|l|}{$\overline{S e x}$} \\
\hline Male & 1439 & 45.8 \\
\hline Female & 1612 & 54.2 \\
\hline \multicolumn{3}{|l|}{ Cause of death } \\
\hline Cancer & 986 & 30.5 \\
\hline Cardiovascular disease & 767 & 25.9 \\
\hline Respiratory failure & 342 & 10.9 \\
\hline Nervous system disease & 551 & 18.6 \\
\hline Other or unknown & 405 & 14.0 \\
\hline \multicolumn{3}{|l|}{ Place of death } \\
\hline Hospital & 1258 & 40.1 \\
\hline Hospice/palliative care unit & 150 & 5.2 \\
\hline Nursing home & 928 & 31.9 \\
\hline Elderly care residence & 372 & 11.9 \\
\hline Home & 332 & 10.7 \\
\hline Other & 7 & 0.2 \\
\hline \multicolumn{3}{|l|}{ Region } \\
\hline German-speaking & 1870 & 74.4 \\
\hline French-speaking & 808 & 20.4 \\
\hline Italian-speaking & 373 & 5.2 \\
\hline \multicolumn{3}{|l|}{ Physician } \\
\hline \multicolumn{3}{|l|}{ Physician's role } \\
\hline Generalist & 2016 & 67.5 \\
\hline Specialist & 993 & 32.5 \\
\hline \multicolumn{3}{|l|}{ Physician graduated } \\
\hline $30+$ years ago & 1028 & 33.6 \\
\hline $15-29$ years ago & 740 & 24.6 \\
\hline$<15$ years ago & 1276 & 41.8 \\
\hline
\end{tabular}

*Unweighted $n$, weighted \%

\section{Frequency of Treatments Withheld, Withdrawn, or Continued}

For $2242(73 \%)$ of the 3051 deceased patients, at least one of the nine specified treatments was either continued until death or withheld or withdrawn. The treatment most commonly mentioned at the end of life was artificial hydration (1496 cases). Artificial hydration was continued until death in 750 cases (23\% of the total study population), withdrawn in 136 cases (4\%), and withheld in 614 cases (22\%; Table 2). In four of the cases, artificial hydration was both withdrawn and withheld: this happened, for instance, when there was a discussion on restarting the treatment after it had once been withdrawn. In cases where artificial hydration was an applicable treatment, therefore, it was forgone in $53 \%$, by far the lowest figure for all the treatments included in the survey. The treatment with the highest percentage forgone was radiotherapy: although only $7 \%$ of the patients overall were eligible for this treatment, it was withheld or withdrawn in $94 \%$ of the cases. Artificial nutrition, surgery, chemotherapy, and dialysis were all forgone in more than $86 \%$ of cases; ventilator therapy and blood/blood products were forgone in $80 \%$ and $79 \%$, respectively; antibiotics were forgone in $70 \%$ of the applicable cases.
Figure 1 shows the frequency of specific treatments continued, withdrawn, or withheld for patients who died in hospitals (including palliative care units), at home (including elderly care residences and others), and in nursing homes. Both withdrawing and continuing treatment were more frequent for people who died in hospitals than for people who died in other places.

\section{Determinants of Withholding Rather than Attempting Potentially Life-sustaining Treatment}

Our study revealed that the four treatments most commonly forgone at the end of life were artificial hydration, artificial nutrition, antibiotics, and ventilator therapy (Table 3). For all four treatments, people who died of organ failure or other reasons were less likely to have their treatment withheld than those who died of cancer. All treatments were more likely to be withheld for people who died in nursing homes or at home than for those who died in hospitals. In particular, artificial hydration was twenty times more likely to be withheld in places outside hospitals. Antibiotics, artificial nutrition, and ventilator therapy were more likely to be withheld for older people and women. Even when controlling for place of death, specialist physicians were less likely to withhold artificial hydration, artificial nutrition, or ventilator therapy than generalists. The length of a physician's career had only a limited effect: physicians who graduated less than 15 years ago were less likely to withhold artificial hydration or antibiotics. All treatments were less likely to be withheld in the French- and Italian-speaking parts of Switzerland than in the Germanspeaking part.

In contrast, we found no significant differences between patient groups nor a significant influence of physician characteristics on the decision to withdraw rather than continue potentially life-sustaining treatment for any of the four treatments (Table 4). Artificial hydration and nutrition, however, were more likely to be withdrawn in the French-speaking region than in the German-speaking region (OR 1.92, 95\% CI 1.22-3.02, and OR 2.35, 95\% CI 1.09-5.04, resp.).

\section{DISCUSSION}

This is the first mortality follow-back study to investigate withholding and withdrawing of potentially life-sustaining treatment, as well as the continuation of such treatment until death. Most potentially life-sustaining treatments are either withheld or withdrawn before the end of life, but there is considerable variation between specific treatments and places of death. The four most common treatments - artificial hydration, nutrition, ventilator therapy, and antibiotics - were withdrawn or withheld 53 to $87 \%$ of the time, with artificial hydration most often being continued until death. Both continuation and withdrawal of treatment were more frequent in hospitals, especially for artificial hydration. Older people and 
Table 2 Applicable Life-sustaining Treatments at the End of Life: Continued Until Death, Withdrawn, and Withheld $(N=2242)$

\begin{tabular}{|c|c|c|c|c|c|c|c|}
\hline \multirow[t]{3}{*}{ Type of treatment } & \multirow{2}{*}{\multicolumn{2}{|c|}{$\begin{array}{l}\text { Treatments } \\
\text { continued }\end{array}$}} & \multicolumn{5}{|c|}{ Treatments forgone } \\
\hline & & & \multicolumn{2}{|c|}{ Withdrawn } & \multicolumn{2}{|c|}{ Withheld } & \multirow[t]{2}{*}{$\%$ forgone of applicable } \\
\hline & $n^{*}$ & $\% * *$ & $n^{*}$ & $\% * * \dagger$ & $n^{*}$ & $\% * * \dagger$ & \\
\hline Artificial hydration & 750 & 22.8 & 136 & 4.2 & 614 & 21.7 & 53.1 \\
\hline Antibiotics & 414 & 12.9 & 262 & 8.5 & 623 & 21.4 & 69.8 \\
\hline Artificial nutrition & 132 & 4.2 & 104 & 3.2 & 705 & 24.3 & 86.6 \\
\hline Ventilator therapy & 171 & 5.2 & 84 & 2.7 & 521 & 17.8 & 79.8 \\
\hline Surgery & 47 & 1.6 & 17 & 0.6 & 347 & 11.9 & 88.9 \\
\hline Chemotherapy & 54 & 1.7 & 90 & 2.8 & 287 & 9.5 & 88.1 \\
\hline Blood and blood products & 72 & 2.3 & 35 & 1.1 & 223 & 7.6 & 78.7 \\
\hline Dialysis & 34 & 1.1 & 39 & 1.3 & 208 & 6.9 & 88.6 \\
\hline Radiotherapy & 12 & 0.4 & 16 & 0.5 & 189 & 6.3 & 93.8 \\
\hline
\end{tabular}

*Unweighted $n$, weighted \%

**As a percentage of total study population $(N=3051)$

${ }^{+}$Number of cases where both withheld and withdrawn were applicable: artificial hydration $=4$, antibiotics $=6$, artificial nutrition $=5$, ventilator therapy $=2$, surgery $=1$, chemotherapy $=2$, blood and blood products $=1$, dialysis $=3$, radiotherapy $=1$

"Percentage of withheld and withdrawn per sum of individuals with respective treatment continued, withdrawn, or withheld

women were more likely to have treatment withheld rather than attempted, with the exception of artificial hydration. Treatment was less likely to be withheld from people who died of cancer than from people who died of causes other than cancer. The impact of physician characteristics was limited, with specialists - even when controlling for place of death - and younger physicians being less likely to withhold certain treatments.

Our study shows how often a variety of treatments are forgone at the end of life in comparison with the continuation of those treatments until death. By using a random sample of nationwide data, we were able to investigate the impact of patient and physician characteristics in different care settings. We were also able to disentangle withdrawing and withholding treatment. Compared with previous research, therefore, our study provides a better representation of continuing and forgoing potentially life-sustaining treatment and offers greater insight into clinical practice.

Previous research has shown that inappropriate drug use at the end of life is common. ${ }^{21,22}$ However, it can be hard to determine whether particular medications have a potentially life-sustaining effect, and thus whether withholding or withdrawing these medications is appropriate. Our study shows that treatments with a potentially high burden - such as chemotherapy — are most often withheld or withdrawn. This is in line with the current ethical understanding of the merits of forgoing treatment when its benefits are small in relation to the risk of harming the patient. ${ }^{5}$ Aggressive treatment, such as chemotherapy, given at the end of life has been recognized as harmful to both the quality of care and the quality of life. ${ }^{23,24}$

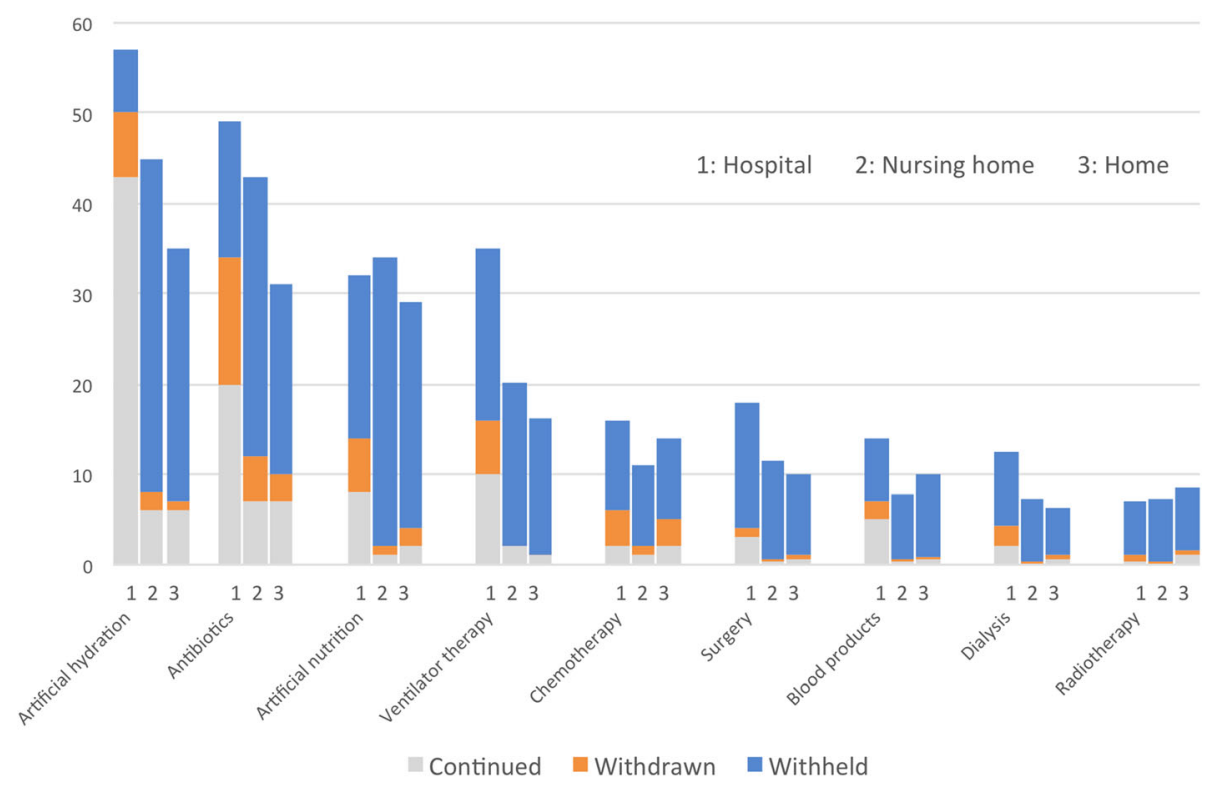

Figure 1 Potentially life-sustaining treatments at the end of life: percentage of cases where treatment was continued to death, withdrawn, or withheld, by place of death $(n=2242)$. Number of cases where treatment was continued, withdrawn, or withheld at the end of life. 'Other' includes home, elderly care residence, and other venues. When treatment was both withheld and withdrawn, it was categorized as withdrawn for the purposes of this figure, as this is the more explicitly life-shortening decision 
Table 3 Logistic Regressions of Withholding the Four Most Common Treatments at the End of Life Compared with Those for Whom That Treatment Was Attempted (Withdrawn or Continued)

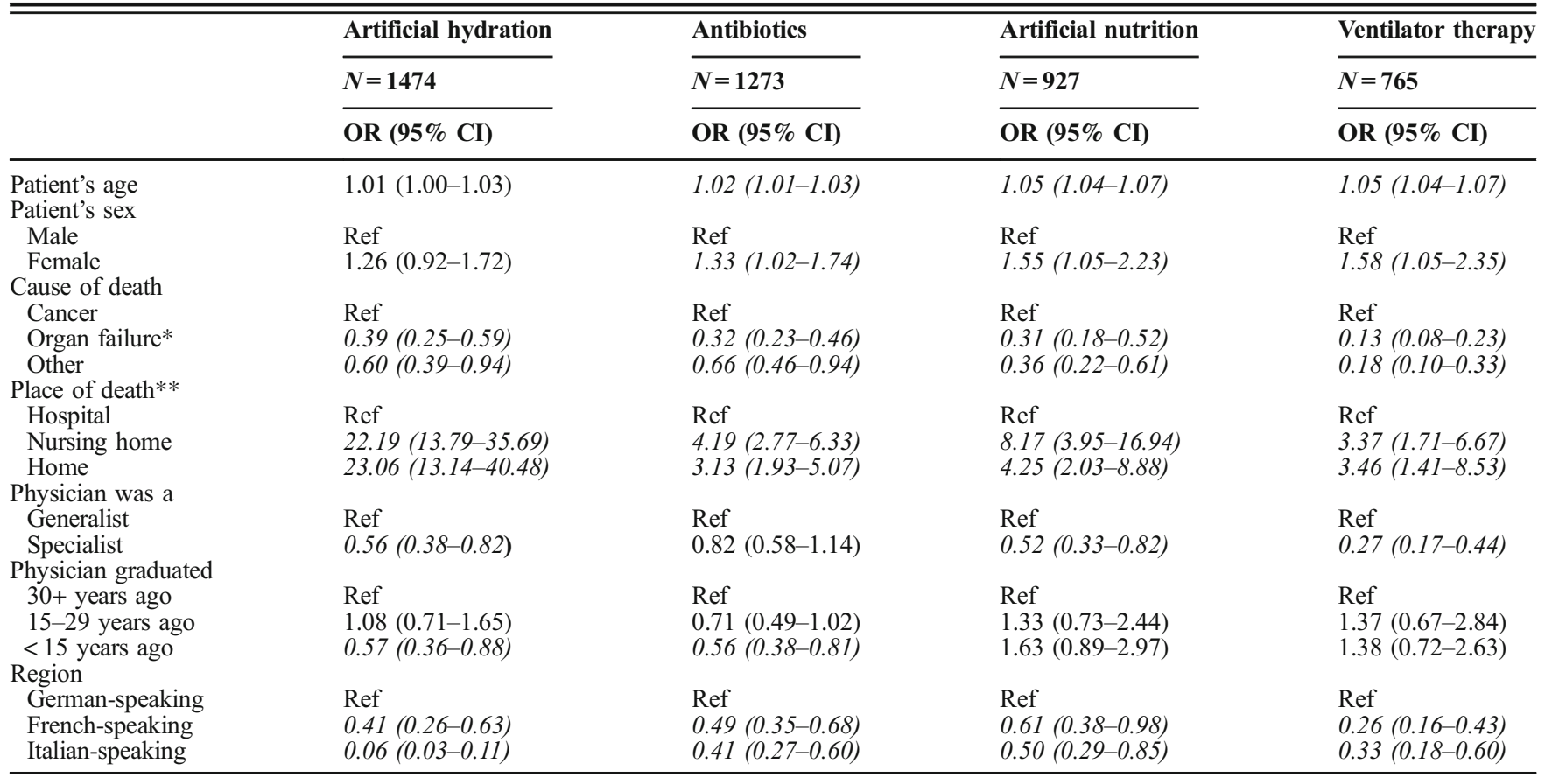

Italic indicates statistical significance $(P<0.05)$

When treatment was both withheld and withdrawn, it was categorized as withdrawn for the purposes of this analysis, as this is the more explicitly lifeshortening decision

Missing on physician role $=8$, years since physician's graduation $=1$

OR, odds ratio; $C I$, confidence interval

*Includes diseases of the circulatory or respiratory system

**Home includes elderly care residences and 'others'. Hospital includes palliative care units

Table 4 Logistic Regressions of Withdrawing the Four Most Common Treatments at the End of Life Compared with Those for Whom That Treatment Was Continued, for People Who Died in Hospital

\begin{tabular}{|c|c|c|c|c|}
\hline & Artificial hydration & Antibiotics & Artificial nutrition & Ventilator therapy \\
\hline & $N=695$ & $N=464$ & $N=191$ & $N=225$ \\
\hline & OR (95\% CI) & OR $(95 \%$ CI) & OR $(95 \%$ CI) & OR $(95 \%$ CI) \\
\hline Patient's age & $1.00(0.98-1.02)$ & $1.01(0.99-1.02)$ & $1.00(0.98-1.02)$ & $0.99(0.97-1.02)$ \\
\hline Patient's sex & & & & \\
\hline Male & Ref & Ref & Ref & Ref \\
\hline Female & $0.75(0.47-1.19)$ & $0.92(0.61-1.38)$ & $0.95(0.47-1.94)$ & $0.95(0.51-1.77)$ \\
\hline Cause of death & & & & \\
\hline Cancer & Ref & Ref & Ref & Ref \\
\hline Organ failure** & $0.78(0.45-1.35)$ & $0.84(0.52-1.35)$ & $0.34(0.15-0.78)$ & $0.50(0.22-1.16)$ \\
\hline Other & $1.06(0.60-1.86)$ & $1.14(0.67-1.93)$ & $0.71(0.31-1.60)$ & $0.74(0.29-1.89)$ \\
\hline Physician was a & & & & \\
\hline Generalist & Ref & Ref & Ref & Ref \\
\hline Specialist & $0.97(0.61-1.55)$ & $1.37(0.91-2.08)$ & $0.71(0.33-1.53)$ & $1.57(0.73-3.38)$ \\
\hline Physician graduated & & & & \\
\hline $30+$ years ago & Ref & Ref & Ref & Ref \\
\hline $15-29$ years ago & $2.06(0.62-6.86)$ & $0.84(0.32-2.18)$ & $0.80(0.20-3.21)$ & $0.83(0.25-2.80)$ \\
\hline$<15$ years ago & $1.95(0.64-5.89)$ & $0.88(0.38-2.05)$ & $0.86(0.25-3.01)$ & $0.96(0.32-2.88)$ \\
\hline Region & & & & \\
\hline German-speaking & Ref & Ref & Ref & Ref \\
\hline French-speaking & $1.92(1.22-3.02)$ & $1.15(0.73-1.79)$ & $2.35(1.09-5.04)$ & $0.96(0.50-1.83)$ \\
\hline Italian-speaking & $1.04(0.50-2.17)$ & $0.67(0.36-1.25)$ & $0.83(0.30-2.30)$ & $0.70(0.26-1.84)$ \\
\hline
\end{tabular}

Italic indicates statistical significance $(P<0.05)$

When treatment was both withheld and withdrawn, it was categorized as withdrawn for the purposes of this analysis, as this is the more explicitly lifeshortening decision

Missing on physician role $=8$, years since physician's graduation $=1$

$O R$, odds ratio; $C I$, confidence interval

**Includes diseases of the circulatory or respiratory system 
The most common treatment continued at the end of life was artificial hydration. The decision to continue, withdraw or withhold artificial hydration played a part in almost half of all deaths and the likelihood of artificial hydration being continued in these cases was nearly $50 \%$. Guidelines on the continuation or discontinuation of artificial hydration and nutrition provide no clear recommendations on the best course of action at the end of life and often just refer to advanced directives and shared decision-making. ${ }^{25}$ While it is commonly understood, particularly in ambulatory and nursing home palliative care settings, that dying patients do not need artificial hydration, many physicians still believe a decision to forgo artificial hydration has some life-shortening effects or that providing intravenous hydration is the minimum standard of care. ${ }^{26,27}$

Differences between places of death in the frequencies of continuing, withdrawing, or withholding treatment were considerable. The four treatments were three to twenty times more likely to be withheld in nursing homes or at home than in hospitals. Treatment decisions may be related to experience with complex end-of-life decisions and ease of access to infrastructure for medical treatment. Our data, however, does not allow any inference on potential overuse in hospitals or underuse in nursing homes. Patients are also more likely to be cared for by specialist physicians in hospitals. Even after controlling for place of death, we found that specialists were less likely to withhold several treatments. Alternatively, people who die at home or in nursing homes may have engaged in more advanced care planning to make their wishes known, which often involves decisions to withhold or withdraw treatment. $^{28}$

A decision to withhold rather than attempt treatment was less likely to be made for those who died of non-cancer causes than for those who died of cancer. However, the cause of death had no impact on the likelihood of withdrawing treatment once it had been started. This suggests that the decision to continue or withdraw treatment may be based more on acute symptoms or prognosis, whereas the decision to attempt or withhold treatment is also influenced by the diagnosis. These differences between the causes of death may be attributable to the difficulty of accurate prognostication for people with noncancer diagnoses or the higher frequency of advanced care planning with people who die of cancer. ${ }^{28,29}$ Our findings that women were more likely to have antibiotics, artificial nutrition, or ventilator treatment withheld are in line with a systematic review that found non-treatment decisions to be more frequent among women. ${ }^{30}$

Our study had a number of limitations. Because the data was retrospective, our study might be susceptible to recall bias on the part of the physicians. This was countered by limiting the time between the patient's death and completing the questionnaire and by the use of medical records as a memory aid. We performed additional analyses for the impact of delayed reporting for all nine specified treatments. We adjusted for place of death and language region, as both experienced delay in questionnaire completion. We did not have access to the cause of death that appeared on the death certificate but relied on broad categories given by the physicians in the questionnaire. A more detailed distinction between different causes of death may have provided better insight into the link between the continuation or forgoing of treatments and patient-specific care needs. Finally, we recorded the place of death instead of the place where the patients spent most of their time at the end of life. This means that there may be a selection bias in the reported frequency of attempted or withheld treatments: those who lived at home or in nursing homes might not have wanted treatment withheld at the end of life, and so might have been transferred to the hospitals where they eventually died.

In conclusion, treatments with a potentially high burden are rarely continued until death. ${ }^{31}$ Treatments with a less clear impact - either burdensome or beneficial-are more often continued. The differences between care settings suggest that decisions are sometimes based on available support rather than guidelines. Our results also suggest that, in clinical practice, the decision to withdraw treatment is based on considerations more similar to the decision to continue treatment than to the decision to withhold treatment. Future studies should collect detailed information on the decision-making process and care in the last phase of life, to ascertain how often the decision to forgo or continue care is in line with best practice. Insight into how physicians understand the potential benefits and burdens of life-sustaining treatments would be valuable in assessing the need for better guidelines and education to improve care at the end of life.

Acknowledgements: We thank the Swiss Federal Statistical Office for having sampled deaths for our study and the Swiss Academy of Medical Sciences (SAMS) for ensuring the anonymity of the questionnaires. We are indebted to the many physicians who participated in the study and filled in the questionnaires.

Further members of the Swiss Medical End-of-Life Decisions Study Group are as follows: Karin Faisst (St. Gallen), Felix Gutzwiller (Zurich), Samia Hurst (Geneva), Christoph Junker (Neuchâtel), Milo Alan Puhan (Zurich), Margareta Schmid (Zurich), and Sarah Ziegler (Zurich).

Corresponding Author: Matthias Bopp, $\mathrm{PhD}, \mathrm{MPH}$; Epidemiology, Biostatistics and Prevention Institute University of Zurich, Zurich, Switzerland (e-mail: matthias.bopp@uzh.ch).

Funding Information This study was funded by the Swiss National Science Foundation (grant 406740-139309, National Research Program 67 'End-of-Life') and the Palliative Care Research funding program of the Swiss Academy of Medical Sciences; the Gottfried and Julia Bangerter-Rhyner Foundation; and the Stanley Thomas Johnson Foundation (grant PC 03/16).

Data Availability The data and the survey tool are available from the authors on request. The survey tool has been published as supplementary material with Ziegler et al. (2018). ${ }^{20}$

\section{Compliance with Ethical Standards:}

Consent from the patient was waived by the Zurich Cantonal Ethics Committee (KEK-StV No. 23/13).

Conflict of Interest: The authors declare that they do not have a conflict of interest. 


\section{REFERENCES}

1. Cheung MC, Earle CC, Rangrej J, et al. Impact of aggressive management and palliative care on cancer costs in the final month of life. Cancer. 2015;121(18):3307-15.

2. Wright AA, Keating NL, Ayanian JZ, et al. Family perspectives on aggressive cancer care near the end of life. Jama. 2016;315(3):284-292.

3. Giannini A, Pessina A, Tacchi EM. End-of-life decisions in intensive care units: attitudes of physicians in an Italian urban setting. Intensive Care Medicine. 2003;29(11):1902-1910.

4. Groenewoud JH, van der Heide A, Kester JGC, de Graaff CLM, van der Wal G, van der Maas P. A nationwide study of decisions to forgo lifesustaining treatment in Dutch medical practice. Arch Intern Med. 2000;160(3):357-363.

5. Welie JVM, ten Have HAMJ. The ethics of forgoing life-sustaining treatment: theoretical considerations and clinical decision making. Multidisciplinary Respiratory Medicine. 2014;9:14.

6. Pereira SM, Pasman HR, van der Heide A, van Delden JJ, OnwuteakaPhilipsen BD. Old age and forgoing treatment: a nationwide mortality follow-back study in the Netherlands. Journal of medical ethics. 2015;41:766-770.

7. van Wijmen MP, Pasman HR, Widdershoven GA, OnwuteakaPhilipsen BD. Continuing or forgoing treatment at the end of life? Preferences of the general public and people with an advance directive. Journal of medical ethics. 2015;41:599-606.

8. Chambaere K, Cohen J, Robijn L, Bailey SK, Deliens L. End-of-Life Decisions in Individuals Dying with Dementia in Belgium. Journal of the American Geriatrics Society. 2015;63(2):290-296.

9. Bosshard G, Nilstun T, Bilsen $\mathbf{J}$, et al. Forgoing treatment at the end of life in 6 European countries. Arch Intern Med. 2005;165(4):401-407.

10. Schmid M, Zellweger U, Bosshard G, Bopp M. Medical end-of-life decisions in Switzerland 2001 and 2013: Who is involved and how does the decision-making capacity of the patient impact. Swiss Med Wkly. 2016; 146:w14307.

11. Bosshard G, Zellweger U, Bopp M, Schmid M, Hurst SA, Puhan MA Faisst K. Medical end-of-life practices in Switzerland: A comparison of 2001 and 2013. JAMA internal medicine. 2016;176(4):555-556.

12. Melltorp G, Nilstun T. The difference between withholding and withdrawing life-sustaining treatment. Intensive Care Med. 1997;23(12): 1264-1267.

13. Rydvall A, Lynöe $\mathbf{N}$. Witholding and withdrawing life-sustaining treatment: a comparative study of the ethical reasoning of physicians and the general public. Critical Care. 2008;12:R13.

14. Swiss Academy of Medical Sciences (SAMS). Management of dying and death. 2018. Available from: https://www.samw.ch/en/Ethics/Ethicsin-end-of-life-care/Guidelines-management-dying-death.html

15. Thomson S, Osborn R, Squires D, Reed SJ. International profiles of health care systems 2011: Australia, Canada, Denmark, England, France, Germany, Iceland, Italy, Japan, the Netherlands, New Zealand, Norway, Sweden, Switzerland, and the United States. Commonwealth Fund pub. 1857

16. Miccinesi G, Fischer S, Paci E, et al. Physicians' attitudes towards endof-life decisions: a comparison between seven countries. Soc Sci Med 2005;60:1961-1974.

17. Onwuteaka-Philipsen BD, Fischer S, Cartwright C, et al. End-of-life decision making in Europe and Australia. A physician survey. Arch Intern Med 2006;166:921-929.
18. Escher M, Perneger TV, Rudaz S, Dayer P, Perrier A. Impact of advance directives and a health care proxy on doctors' decisions: a randomized trial. Journal of pain and symptom management. 2014 Jan 1;47(1):1-1.

19. Silveira MJ, Wiitala W, Piette J. Advance directive completion by elderly Americans: a decade of change. Journal of the American Geriatrics Society. 2014 Apr;62(4):706-10.

20. Ziegler S, Schmid M, Bopp M, Bosshard G, Puhan MA. Using sedative substances until death: A mortality follow-back study on the role of healthcare settings. Pall Med 2019;33(2):213-220.

21. West E, Costantini M, Pasman HR, Onwuteaka-Philipsen B. A comparison of drugs and procedures of care in the Italian hospice and hospital settings: the final three days of life for cancer patients. BMC health services research. 2014;14(1):496.

22. Stroka, Magdalena A. Drug overprescription in nursing homes: an empirical evaluation of administrative data. The European Journal of Health Economics. 2016;17(3): 257-267.

23. Earle CC, Landrum MB, Souza JM, Neville BA, Weeks JC, Ayanian JZ. Aggressiveness of cancer care near the end of life: is it a quality-of-care issue? Journal of Clinical Oncology. 2008 Aug 10;26(23):3860.

24. Prigerson HG, Bao Y, Shah MA, Paulk ME, LeBlanc TW, Schneider BJ, Garrido MM, Reid MC, Berlin DA, Adelson KB, Neugut AI. Chemotherapy use, performance status, and quality of life at the end of life. JAMA oncology. 2015 Sep 1;1(6):778-84.

25. Druml C, Ballmer PE, Druml w, et al. ESPEN guideline on ethical aspects of artificial nutrition and hydration. Clinical Nutrition. 2016;35(3):545-556.

26. Bükki J, Unterpaul T, Nübling G, Jox RJ, Lorenzl S. Decision making at the end of life-cancer patients' and their caregivers' views on artificial nutrition and hydration. Supportive Care in Cancer. 2014;22(12):32873299.

27. Morita Y, Shima Y, Adachi I. Attitiudes of Japanese physicians toward terminal dehydration: A nationwide survey. Journal of Clinical Oncology. 2002;20(24):4699-4704.

28. Brinkman-Stoppelenburg A, Rietjens JA, van der Heide A. The effects of advance care planning on end-of-life care: a systematic review. Palliative medicine. 2014;28(8):1000-1025.

29. De Vleminck A, Pardon K, Beernaert K, Deschepper R, Houttekier D, Van Audenhove C, Deliens L, Vander Stichele R. Barriers to advance care planning in cancer, heart failure and dementia patients: a focus group study on general practitioners' views and experiences. PloS one. 2014;9(1):e84905.

30. Rietjens JA, Deschepper R, Pasman R, Deliens L. Medical end-of-life decisions: does its use differ in vulnerable patient groups? A systematic review and meta-analysis. Soc Sci Med. 2012;74(8):1282-1287.

31. Esserman LJ, Thompson IM, Reid B. Overdiagnosis and overtreatment in cancer: an opportunity for improvement. Jama. 2013 Aug 28;310(8):797-8

Publisher's Note: Springer Nature remains neutral with regard to jurisdictional claims in published maps and institutional affiliations. 